\title{
Application of Synchrotron Radiation-based Methods for Environmental Biogeochemistry: Introduction to the Special Section
}

\author{
Ganga M. Hettiarachchi, ${ }^{*}$ Erica Donner, and Emmanuel Doelsch
}

\begin{abstract}
Tounderstand the biogeochemistry of nutrientsand contaminants in environmental media, their speciation and behavior under different conditions and at multiple scales must be determined. Synchrotron radiation-based $\mathrm{X}$-ray techniques allow scientists to elucidate the underlying mechanisms responsible for nutrient and contaminant mobility, bioavailability, and behavior. The continuous improvement of synchrotron light sources and X-ray beamlines around the world has led to a profound transformation in the field of environmental biogeochemistry and, subsequently, to significant scientific breakthroughs. Following this introductory paper, this special collection includes 10 papers that either present targeted reviews of recent advancements in spectroscopic methods that are applicable to environmental biogeochemistry or describe original research studies conducted on complex environmental samples that have been significantly enhanced by incorporating synchrotron radiation-based X-ray technique(s). We believe that the current focus on improving the speciation of ultra-dilute elements in environmental media through the ongoing optimization of synchrotron technologies (e.g., brighter light sources, improved monochromators, more efficient detectors) will help to significantly push back the frontiers of environmental biogeochemistry research. As many of the relevant techniques produce extremely large datasets, we also identify ongoing improvements in data processing and analysis (e.g., software improvements and harmonization of analytical methods) as a significant requirement for environmental biogeochemists to maximize the information that can be gained using these powerful tools.
\end{abstract}

\section{Core Ideas}

- SR-based techniques have revolutionized the field of environmental biogeochemistry.

- Improvements to light sources will provide SR with extreme brightness and coherence.

- This should be met with similar advances to synchrotron-related hardware and software.

- Environmental biogeochemists can drive the new advances in the synchrotron science.

- Advances in SR will enable future breakthroughs in environmental biogeochemistry.

Copyright $\odot$ American Society of Agronomy, Crop Science Society of America, and Soil Science Society of America. 5585 Guilford Rd., Madison, WI 53711 USA.

All rights reserved.

J. Environ. Qual. 46:1139-1145 (2017).

doi:10.2134/jeq2017.09.0349

This is an open access article distributed under the terms of the CC BY-NC-ND

license (http://creativecommons.org/licenses/by-nc-nd/4.0/)

Received 4 Sept. 2017.

Accepted 26 Sept. 2017.

*Corresponding author (ganga@ksu.edu).
$\mathrm{E}$ NVIRONMENTAL biogeochemistry is an extremely diverse and wide-ranging scientific field with cross-cutting research themes emphasizing the interplay between inorganic and organic compounds within soils and sediments, waters, air, and biota. It is an interdisciplinary subfield of the earth sciences, life sciences, and chemistry that brings together microbiologists, biologists, chemists, geochemists, soil scientists, oceanographers, ecologists, and environmental engineers interested in the biogeochemistry of terrestrial, aquatic and atmospheric environments (Berthelin, 1991). Studies in environmental biogeochemistry are conducted at different scales, from the mechanisms or kinetics of reactions at molecular (or cellular) level to the mass transfer or energy flow at ecosystem, regional, or global levels. The biggest challenge for environmental biogeochemistry is extrapolation of molecular-level knowledge to system or global levels. Models are frequently used to help understand the global cycling of nutrients and contaminants, and they need to be based on an accurate understanding of the fundamental mechanisms driving these cycles at the molecular or cellular level (Lombi et al., 2011b). Advanced spectroscopic techniques play an essential role in advancing our fundamental understanding of these reaction processes. However, due to the diversity, complexity, and interactions of these processes, these studies often require the integration of complementary research techniques.

A synchrotron is a large building-sized machine that accelerates charged particles such as electrons (most commonly) and positrons, to extremely high energies. The electrons are accelerated to almost the speed of light (relativistic electrons), and when they are forced to move along curved trajectories by applied magnetic fields, they emit extremely intense electromagnetic radiation called synchrotron radiation (SR, also known as synchrotron light). This very bright light is emitted tangentially to the direction of the circulating electrons' motion. Synchrotron radiation was first observed in 1947 at the General Electric laboratories in the United States (Robinson, 2009), and its usefulness for condensed matter research was first recognized in the late 1960s. Since that time, there has been explosive growth in

G.M. Hettiarachchi, Dep. of Agronomy, 2107 Throckmorton Plant Sciences Center, Kansas State Univ., Manhattan, KS 66506; E. Donner, Univ. of South Australia, Future Industries Institute, Mawson Lakes Campus, SA 5095, Australia; E. Doelsch, CIRAD, UPR Recyclage et risque, F-34398 Montpellier, France. Contribution no. 18-181-J from the Kansas Agricultural Experiment Station. Assigned to Associate Editor Tsutomu Ohno.

Abbreviations: EXAFS, extended X-ray absorption fine structure; GSECARS, GeoSoilEnviro Center for Advanced Radiation Source; NEXAFS, near-edge X-ray fine structure; SR, synchrotron radiation; STXM, scanning transmission X-ray microscopy; XANES, X-ray absorption near edge structure; XAS, X-ray absorption spectroscopy; XRF, X-ray fluorescence; XRM, X-ray microprobes. 
the use of SR for research applications. Due to the usefulness of $S R$, many accelerators today are not dedicated to accelerator physics but exist solely to generate light for SR-based scientific experiments. Synchrotron radiation covers a very broad and continuous spectral range from the infrared up to the hard $\mathrm{X}$-ray region. Its significant properties include high intensity, naturally narrow angular collimation, high degree of polarization, pulsed time structure, and high beam stability, and all of these properties can be quantitatively evaluated (Balerina and Mobilio, 2015). The high brightness of SR is due to the small cross-section of the electron beam and the high degree of collimation. Although the application of SR-based imaging and analysis techniques in environmental biogeochemistry only began about half a century ago, the special properties of SR have meant that SR-based imaging and analysis techniques have revolutionized research in environmental biogeochemistry. For example, combining advanced imaging and analytical techniques with other novel sample preparation techniques, we have been able to advance our understanding of the fundamental processes involved in carbon cycling in soil (Lehmann and Solomon, 2010; Solomon et al., 2012). Lehmann et al. (2008) were the first to couple near-edge X-ray fine structure (NEXAFS)-scanning transmission X-ray microscopy (STXM) with an innovative soil preparation method that preserves the spatial assemblage of the soil aggregates. They used this approach to demonstrate the spatial complexity of soil organic matter at the nanometer scale. Peth et al. (2014) combined novel staining techniques with microscale-computed tomography $(\mathrm{CT})$ to visualize the presence of soil organic matter in three-dimensional soil space. The combination of micrometer-scale X-ray fluorescence (XRF) imaging and $\mathrm{X}$-ray absorption spectroscopy techniques (such as X-ray absorption near-edge spectroscopy [XANES] or extended $\mathrm{X}$-ray absorption fine-structure spectroscopy [EXAFS]) is an extremely useful and increasingly popular, nondestructive approach for studying trace element distribution, associations, and speciation in environmental samples. It has been used in numerous studies to investigate selected points of interest in soils (Manceau et al., 2004; Nachtegaal et al., 2005; Arai et al., 2006), wastes (Hettiarachchi et al., 2006; Al-Abed et al., 2008; Legros et al., 2010), and plants (Seyfferth et al., 2010; Castillo-Michel et al., 2011; Moore et al., 2014). Until recently, scanning fluorescence-XANES imaging has not been applied to investigate large sample areas, as scanning through a focused pencil beam to measure a XANES spectrum at each point is very time consuming. However, recent advances in XRF detection have made this approach feasible at some beamlines. For example, Etschmann et al. (2014) used megapixel fluorescence-XANES imaging to explore the heterogeneity of $\mathrm{Cu}$ speciation in a complex environmental matrix at the micrometer scale to identify the spatial distribution of minor species that cannot be assessed by conventional methods. Another exciting possibility is combining in situ phylogenetic analysis (such as fluorescence in situ hybridization [FISH]) with SR-based techniques (such as $\mu$-XAFS [X-ray absorption fine structure]) to observe the biological inferences that affect speciation and distribution of elements in geomaterials. Here, Mitsunobu et al. (2012), who coupled XAFS and molecular biology to observe in situ the biogenic oxidation and reduction reactions in soils, can be considered as an example.
Continuous advancement and improvements to synchrotron rings and beamlines continue to improve the information available to environmental biogeochemists. In fact, synchrotron facilities now play a vital and irreplaceable role in many areas of environmental biogeochemistry because they enable scientists to investigate the distribution and speciation of contaminants and nutrients under in situ conditions in complex environmental materials at environmentally relevant concentrations. Figure 1, updated from Lombi et al. (2011b), shows results from a search of three leading journals in the field of environmental science (Journal of Environmental Quality, Environmental Pollution, and Environmental Science \& Technology) for publications including the words "EXAFS" and "XANES." It is clear that the number of publications including these two techniques continues to rise, and this indicates a significant reliance on synchrotron techniques for advanced environmental studies (Fig. 1). The use of advanced analytical techniques such as SR-based X-ray techniques in environmental biogeochemistry research is slowly but steadily increasing, and their applications are broadening (Table 1). Some new advancements in SR-based techniques and beamlines of particular relevance for environmental biogeochemistry are presented in this special section (Proux et al., 2017; Sutton et al., 2017); however, it is not our intention to provide a thorough review of all SR-based techniques, so for more comprehensive information, please refer to de Jonge et al. (2014), Lombi and Susini (2009), or Thieme et al. (2007).

The worldwide distribution of synchrotron light sources shows that they are currently spread across five continents (Fig. 2). Today, there are $\sim 50$ synchrotron light sources worldwide and their beamline capabilities continue to evolve (Lightsources, 2016). This evolution will facilitate scientific discoveries (Owen et al., 2016) in many fields. A famous quote by Sydney Brenner in 1980, cited by many times before (Robertson, 1980), states that "progress in science depends on new techniques, new discoveries, and new ideas, probably in that order." It is certainly well understood and accepted by environmental biogeochemists that there are significant challenges and limitations for any technique when diluted analytes are investigated in complex matrices, and that ongoing improvements in synchrotron techniques

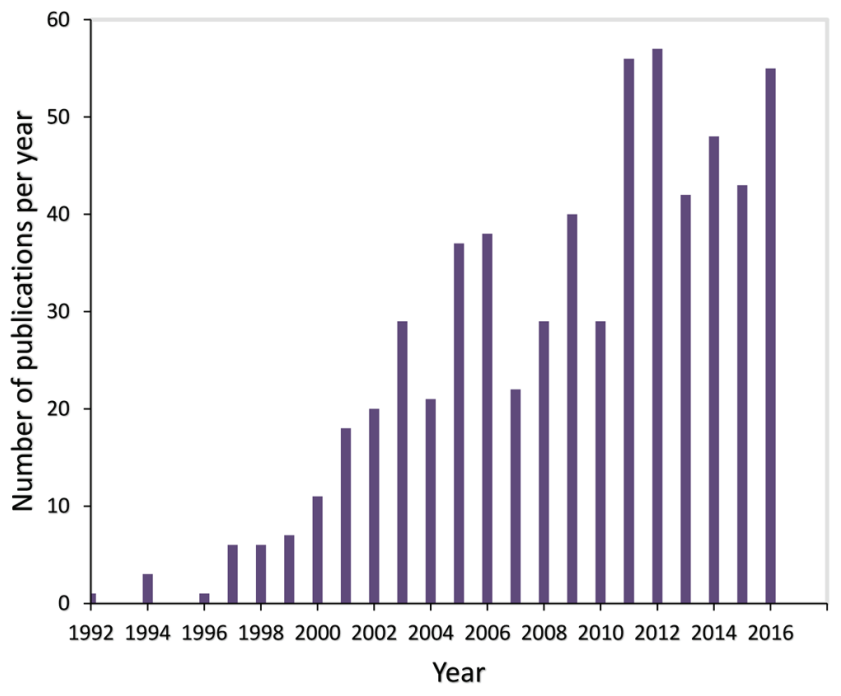

Fig. 1. Number of scientific articles (per year) published in three leading environmental journals including either the word "EXAFS" (extended X-ray absorption fine structure) or "XANES" (X-ray absorption near edge structure ) in their text (updated from Lombi et al. 2011a). 
Table 1. Synchrotron radiation-based analytical techniques commonly used in environmental biogeochemistry research and examples of their applications.

\begin{tabular}{ll}
\hline Analytical technique & \multicolumn{1}{c}{ Examples for applications } \\
\hline $\begin{array}{l}\text { Bulk-X-ray absorption spectroscopy } \\
\begin{array}{l}\text { Bulk-extended X-ray fine structure } \\
\text { spectroscopy (EXAFS) }\end{array}\end{array}$ & $\begin{array}{l}\text { Speciation of elements (contaminants, nutrients, } \\
\text { etc.) in numerous environmental samples such } \\
\text { as atmospheric aerosols, dust, plants, soils, }\end{array}$ \\
sediments and various waste materials, etc. & $\begin{array}{l}\text { Speciation of elements in numerous } \\
\text { environmental samples such as atmospheric } \\
\text { aulk-X-ray absorption near-edge structure } \\
\text { spectroscopy (XANES) }\end{array}$ \\
& $\begin{array}{l}\text { aeroste materials, etc., especially useful for studies } \\
\text { focusing on the oxidation state of elements }\end{array}$
\end{tabular}

Micro-X-ray absorption spectroscopy $\mu$-XANES

Micro-extended XAFS ( $\mu$-EXAFS)

Synchrotron radiation-based X-ray photoelectron spectroscopy (XPS)

Micro- and nanoscale X-ray fluorescence spectroscopy (XRF)

Synchrotron radiation-based X-ray diffraction (SR-XRD)

High-energy resolution XAS (high-energy resolution fluorescence detected [HERFD] $X A N E S$; high-energy resolution auger detection [HERAD] XANES)

X-ray $\mu$-tomography

Scanning transmission X-ray microscopy (STXM)-near-edge X-ray fine structure (NEXAFS) spectroscopy

STXM-low-energy XRF detection
Spatially resolved elemental speciation in numerous environmental samples such as atmospheric aerosols, plants, soils, sediments, focusing on the oxidation state of elements Spatially resolved elemental speciation in numerous environmental samples such as atmospheric aerosols, plants, soils, sediments, and mine wastes, etc.

Surface chemistry of minerals and solids and characterization of nanomaterials

Elemental distribution and associations in soil, sediments, dust, plant tissues, roots, animal tissues, soil aggregates

Detection of crystalline trace precipitates in environmental mediums due to better collimation and lower spectral overlapping

Precise determination of the local structure around the absorbing atom

Speciation of XAS nonsensitive elements such as $\mathrm{Pb}$ in soils, sediments, etc. Speciation of trace elements (diluted) in environmental mediums geometry, and physical processes If conducted in fluorescence mode, this method is also element specific and allows spatially resolved element maps to be generated.

Characterizing organic matter, microaggregates, microorganisms, speciation of $\mathrm{C}, \mathrm{N}, \mathrm{P}$, and $\mathrm{S}$ at the $\mathrm{K}$ - absorption edges and $\mathrm{Al}, \mathrm{Ca}$, and $\mathrm{Fe}$ speciation using L-edge NEXAFS

Imaging of nanoscale biomineral formation, microbial-elemental interactions Speciation and quantitation of diluted elements (such as As) in bacteria and mine wastes, etc., especially useful for studies

Aggregate microstructure, pore network
Datta et al. (2012), Al-Abed et al. (2008), Burke et al. (2012), Cances et al. (2005), Blamey et al. (2015), Bodei et al. (2007)

Takahashi et al. (2006), Burke et al. (2012), Galkaduwa et al. (2017), Sarret et al. (2005)

Castillo-Michel et al. (2011), Smith et al. (2009a), Bacquart et al. (2007), Arai et al. (2003, 2006), Karna et al. (2016)

Manceau et al. (2004), Mitsunobu et al. (2012), Baker et al. (2012), Strawn and Baker (2009)

Papaefthimiou et al. (2011)

Kyriacou et al. (2014), Moore et al. (2014), Seyfferth et al. (2010), Spielman-Sun et al. (2017)

Baker et al. (2012), Manceau et al. (2004)

Llorens et al. (2012), Manceau et al. (2016), Swarbrick et al. (2009)

Bhreasail et al. (2012), Wang et al. (2012), Peth et al. (2014), Smith et al. (2009b)

Wan et al. (2007), Lehmann et al. (2008), Behrens et al. (2012), Solomon et al. (2012), Chen et al. (2014), Peth et al. (2014)

Hitchcock et al. $(2010,2012)$
Access to synchrotron facilities for the general user community is granted on a merit basis, where users from any discipline anywhere in the world can submit a proposal and proposals are assessed on a competitive basis according to established criteria focusing on the scientific purpose and significance of the proposed experiment. Demand for access to SR-based techniques by highly active environmental biogeochemists continues to increase, and it is becoming increasingly difficult to obtain beamtime to conduct research using the newer and/or less common techniques and beamlines, such as STXM-NEXAFS, for environmental biogeochemistry research. An increase in the number of such beamlines and the amount of beamtime available for the user community is needed to permit more reliable access to these techniques. 1a. Wallander and Wallentin, 2017). Improvements sample environments and shorter data acquisition time can help to circumvent this problem. 


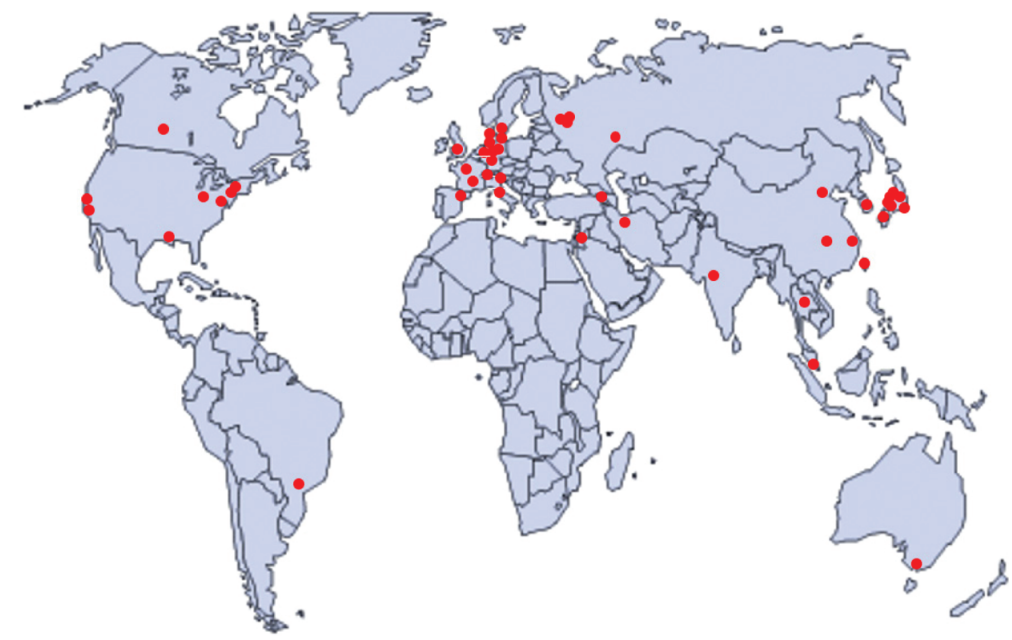

\begin{tabular}{|c|c|c|c|c|}
\hline \multicolumn{5}{|c|}{ Continent } \\
\hline Asia & Australia & Europe & North America & South America \\
\hline ASRC & AS $\left(3^{\text {rd }}\right)$ & $\operatorname{ALBA}\left(3^{\text {rd }}\right)$ & ALS & LNLS \\
\hline CANDLE & & ANKA & $\operatorname{APS}\left(3^{\text {rd }}\right)$ & \\
\hline CAT & & DAFNE & CAMD & \\
\hline BSRF & & DELSY & CHESS & \\
\hline HISOR & & DELTA & CLS & \\
\hline ILSF & & DIAMOND & NSLS-II $\left(3^{\text {rd }}\right)$ & \\
\hline NSRL & & ELETTRA & SSRL & \\
\hline NSRRC & & ELSA & SURF & \\
\hline PF & & ESRF & & \\
\hline PLS & & HZB & & \\
\hline RitsSR & & ISA & & \\
\hline SAGALS $\left(3^{\text {rd }}\right)$ & & KSRS & & \\
\hline SESAME & & MAX IV & & \\
\hline SLRI & & MLS & & \\
\hline SPring-8 & & PETRA III & & \\
\hline SSLS & & $\operatorname{SLS}\left(3^{\text {rd }}\right)$ & & \\
\hline SSRC & & SOLARIS $\left(4^{\text {th }}\right)$ & & \\
\hline $\operatorname{SSRF}\left(3^{\text {rd }}\right)$ & & SOLEIL $\left(3^{\text {rd }}\right)$ & & \\
\hline UVSOR & & TNK & & \\
\hline
\end{tabular}

Abbreviations:

ALS - Advanced Light Source ANKA - Angstromquelle Karlsruhe APS - Advanced Photon Source ASRC - Aichi Synchrotron Radiation Center AS - Australian Synchrotron BSRF - Beijing Synchrotron Radiation Facility CAMD - Center for Advanced Microstructures and Devices

CANDLE - Center for the Advancement of Natural Discoveries using Light Emission CAT - Centre for Advanced Technology CHESS - Cornell High Energy Synchrotron Source CLS - Canadian Light Source

DELSY - Dubna Electron Synchrotron DELTA - Dortmund Electron Storage Ring Facility ELETTRA- Elettra Synchrotron Light Laboratory ELSA - Electron Stretcher Accelerator ESRF- European Synchrotron Radiation Facility HISOR - Hiroshima Synchrotron Radiation Center

HZB - Helmholtz-Zentrum Berlin ILSF - Iranian Light Source Facility ISA - Institute for Storage Ring Facilities KSRS - Kurchatov Synchrotron Radiation Source LNLS - Laboratorio Nacional de Luz Sincrotron
MLS - Metrology Light Source

NSLS-II - National Synchrotron Light Source II NSRL - National Synchrotron Radiation Laboratory

NSRRC - National Synchrotron Radiation Research Center

PETRA III - PETRA III at DESY

PF - Photon Factory

PLS - Pohang Light Source

RitsSR - Ritsumeikan University SR Center

SAGALS - Saga Light Source

SESAME - Synchrotron-light for Experimental Science and Applications in the Middle East

SLRI - Synchrotron Light Research Institute SLS - Swiss Light Source

SOLARIS - National Synchrotron Radiation Centre SOLARIS

SPring-8 - Super Photon ring-8 GeV SSLS - Singapore Synchrotron Light Source SSRC - Siberian Synchrotron Research Centre SSRF - Shanghai Synchrotron Radiation Facility

SSRL - Stanford Synchrotron Radiation Lightsource

SURF- Synchrotron Ultraviolet Radiation Facility UVSOR - Ultraviolet Synchrotron Orbital Radiation Facility

\section{Summaries of Papers in This Special Section}

Although this special collection of articles does not intend to cover the full spectrum of advanced in situ spectroscopic techniques, it represents a good cross-section of the most popular techniques used in environmental biogeochemistry and provides examples of their applications to study environmentally important nutrients and contaminants in natural samples.

\section{Advancements in SR-Based Research Techniques}

Determining the speciation of highly dilute trace elements in environmental media is one of the major challenges facing environmental biogeochemistry researchers, as the speciation of nutrients and contaminants largely determines their bioavailability, mobility, and fate. Due to the difficulties inherent in this challenge, studies reporting the speciation of trace elements in plants or organisms, at environmentally realistic concentrations, and in vivo or under natural conditions, are rare. Giving examples, Proux et al. (2017) discusses the use of an innovative synchrotron spectroscopy technique called high-energy resolution fluorescence detected X-ray absorption spectroscopy (HERFD-XAS). This technique uses a crystal analyzer spectrometer (CAS), which allows XAS signals to be measured in fluorescence mode with an energy resolution of $\sim 1 \mathrm{eV}$; this can be compared with typical energy resolutions of $\sim 150$ to $300 \mathrm{eV}$ for traditional solid-state detectors (SSD) or silicon drift detectors (SDD). This technique provides new opportunities, such as the possibility to study ultra-diluted elements by filtering background photons with great efficiency and improving the sensitivity of the measurements with acquisition of better-resolved XANES spectra, which could revolutionize our ability to accurately determine the speciation of dilute elements in biological and geological samples (Proux et al., 2017). It is exciting to see that there are beamlines (for example, the FAME-UHD, or the French absorption spectroscopy beamline in material and environmental sciences at ultra-high dilution at the European Synchrotron Research Facility, Grenoble, France; and the I20 beamline at the Diamond Light Source, Didcot, UK) devoted particularly to the study of highly dilute chemical elements, and these beamlines are continuously being modified to enhance their analytical capabilities (Burke et al., 2015; Net et al., 2015).

Synchrotron radiation-based X-ray microprobes (XRM) are powerful tools for environmental biogeochemistry research. Since its first commissioning experiments (energy-dispersive diffraction) in September 1996, the GeoSoilEnviro Center for Advanced Radiation Sources (GSECARS) has provided environmental biogeochemists and other earth

Fig. 2. Worldwide distribution of synchrotron light sources (figure credit M.B. Galkaduwa, Kansas State University). 
scientists with access to high-brilliance, hard X-rays from the Advanced Photon Source's third-generation synchrotron light source to conduct pioneering research work. In their review paper, Sutton et al. (2017) discussed the XRM instrumentation, techniques, and applications, demonstrating their existing capabilities, as well as the prospects for further improvements associated with the proposed upgrade of the Advanced Photon Source. Among the major advancements at the GSECARS facility is the new 3.6-cm-period undulator used by the XRM, which allows access to lower-energy absorption edges than previously accessible. The new capabilities at GSECARS allows high-spatial-resolution XAFS spectra to be collected sequentially on absorption edges down to $2.3 \mathrm{keV}$ (sulfur K edge) and high-energy edges up to $28 \mathrm{keV}$ (cadmium $\mathrm{K}$ edge) on the same sample spot. Another advancement is the availability of high-speed digital flat-panel detectors that are optimized for X-ray diffraction. This allows real-time imaging of diffracted X-rays from a sample in combination with high-speed $\mu$-XRF imaging.

\section{Integrated Approaches}

Soil is a highly heterogeneous and very complex medium composed of inorganic and organic solids, water, and air. Understanding the interactions between organic matter and inorganic components in soils is needed to understand soil carbon sequestration, as well as global cycling of carbon, nutrients, and metals. Imaging techniques allow us to gather spatial information on organo-mineral associations. Scanning electron microscopy (SEM) and transmission electron microscopy (TEM) are widely used to obtain information on the arrangement of organomineral associations. Although both of those two approaches are not species sensitive, when coupled to electron-dispersive X-ray microscopy or electron energy loss spectroscopy (EELS), these techniques can be used to identify mineral species and/or metal valance ratios, as discussed by Stuckey et al. (2017) in this issue. Scanning transmission X-ray microscopy is a powerful SR-based technique that uses soft, high-flux X-ray photons to map micrometer-sized environmental samples with nanometer spatial resolution (Jacobsen et al., 2000). When STXM is coupled with NEXAFS (STXM-NEXAFS spectromicroscopy), it can be used for spectral fingerprinting of fine structures. This approach has contributed to the greatest set of advancements in the understanding of soil organo-mineral interactions in recent years (Stuckey et al., 2017).

Integration of micro- or nanoscale XRF with XAS analyses allows the in situ analysis of metal(loid)s in soils and plants. Kopittke et al. (2017) presents a comprehensive overview on the use of these SR-based X-ray techniques to elucidate the speciation, distribution, uptake, acquisition, and compartmentalization of trace metal(loid)s in plants. These authors also point out that it is necessary to consider complementing synchrotron-based techniques with other experimental approaches, such as nanoscale secondary ion mass spectroscopy (NanoSIMS), laser ablation inductively coupled plasma mass spectrometry (LA-ICP-MS), proton-induced X-ray emission microscopy (micro-PIXE), or electron microscopy, to satisfactorily answer the full diversity of hypotheses arising in environmental biogeochemistry.

Integrating spectroscopic analyses at multiple scales, from the millimeter scale to the submicron scale, is useful for identifying nutrient or contaminant species diversity in highly heterogeneous environmental media, such as soils, with a high degree of specificity. This approach is important when developing in situ remediation technologies for contaminants (Nachtegaal et al., 2005; Arai et al., 2006) and for assessing and managing the potential environmental risks of excess nutrients (Hesterberg et al., 2017). Hesterberg et al. (2017) discusses how precise management of soil phosphorus to meet competing demands from agriculture and environmental protection can benefit from more comprehensive characterization of $\mathrm{P}$ speciation in soils by integrating both bulk or millimeter-scale and spatially resolved nanoscale XANES. They show that spatially resolved nanoscale XANES are more species sensitive and better able to show some missing species in comparison with millimeter-scale analysis, and they discuss how these species may be useful for connecting speciation to the chemical reactivity and mobility of $P$ in soils.

\section{Fate and Bioavailability of Contaminants in Soils}

Bioavailability of soil contaminants largely depends on their speciation in soils. Some contaminant species are more soluble and bioavailable, whereas some species are more stable and less bioavailable. Regardless of the original source, contaminant elements can undergo different biochemical reactions in soil and be in association with different soil constituents, depending on the soil $\mathrm{pH}$, redox potential, and availability of other associated elements. Using XAS, Sekine et al. (2017) investigated the shortterm $(<5 \mathrm{~d})$ aging profile and the long-term $(135 \mathrm{~d})$ speciation of dissolved $\mathrm{Cu}, \mathrm{CuO}$, and $\mathrm{CuS}$ nanoparticles. Their work showed that although the short-term reactions of nanomaterials are dependent on the $\mathrm{Cu}$ form and soil chemistry (e.g., $\mathrm{pH}$ ), in the long term, irrespective of their original form, all of the examined forms of $\mathrm{Cu}$ nanoparticles transformed into $\mathrm{Cu}$ bound to iron oxyhydroxide or natural organic matter.

Colzato et al. (2017) studied short-term temporal changes in $\mathrm{Cd}$ speciation and long-term changes in Cd extractability in relation to the properties of highly weathered Brazilian Oxisols and less weathered Mollisols and Entisols. Cadmium L-edge XANES showed that $\mathrm{Cd}$ was mainly sequestered as $\mathrm{Cd}$ bound to organic matter and to $\mathrm{Fe}$ and $\mathrm{Al}$ oxides (or montmorillonite in the smectite-rich soil sample). However, chemical fractionation showed that the attenuation of soil applied Cd was not progressing over times of up to 4 mo.

Community gardening initiatives in urban areas are thriving due to increasing societal interest in sustainable practices, and a growing demand for fresh, locally grown food. Effective in situ mitigation strategies to minimize the effect of soil contaminants in urban soils on human health are becoming increasingly important as more community gardens are established. Using XAS, Attanayake et al. (2017) studied how compost amendments affected soil Pb speciation in the field and examined the change in soil $\mathrm{Pb}$ speciation during an in vitro bioaccessibility extraction test. Although the short-term effects of compost addition on $\mathrm{Pb}$ speciation were not clear, they found that the fraction of $\mathrm{Pb}$ bound to organic matter increased as the soil-compost mixture aged in the field.

The importance of considering bioavailability for the risk assessment of soil contaminants has gained much attention over the past couple decades. Karna et al. (2017) provides an example of how a synchrotron-based XAS technique can be used to validate in vitro bioaccessibility test results. Their research focused on two of the most common soil contaminants, $\mathrm{Pb}$ and $\mathrm{As}$, and 
examined how speciation and bioaccessibility change as a function of soil particle size.

Natural attenuation of soil contaminants (the processes by which the mobility, bioavailability, and toxicity of the contaminants introduced to soils decline over time), or the aging effect, is a well-known phenomenon (Ma et al., 2006). Mariet et al. (2017) combined speciation and extractability to study $\mathrm{Pb}$ left in soils for several centuries after metallurgical activities. Using EXAFS, they found that $\mathrm{Pb}$ was mainly sorbed to Fe oxy(hydr) oxides and attributed weakly acid-soluble $\mathrm{Pb}$ fractions to the reversibility of $\mathrm{Pb}$ bound to oxy(hydr)oxides. This observation has important environmental consequences and considerations, and the authors attributed this lack of aging effect to the acidic $\mathrm{pH}$ of the soil.

\section{Bright and Exciting Future}

Synchrotron science is undergoing a new revolution with the advent of multiband acromat lattices to achieve diffractionlimited storage rings (Eriksson et al., 2014; Eriksson and van der Veen, 2014). This will deliver SR with unprecedented brightness and coherence. This progress in SR will need to be met by similar advances in optics, beamline, and detector technologies to realize its full potential. Also, there will be the need to develop sampling environments, especially cryosystems, to reduce beam damage due to the increased flux (unless we become much more efficient at collecting signal). All of this will result in a data deluge that will require new ways to store and analyze data to extract increasing amounts of information. It is important to continue to make progress in all aspects of synchrotron-related hardware and software, as the weakest component will likely limit the quality of the new science being delivered. Strong linkages between these components can be achieved through continued communication between environmental biogeochemists and experts in synchrotron techniques and data analysis. It seems that many advances have come about because of partnerships between the earth and environmental science and the synchrotron communities. We believe that the environmental biogeochemistry community can help to drive the synchrotron technology advances in the synchrotron science by developing creative new research ideas. We are optimistic and looking forward to the future breakthroughs in environmental biogeochemistry that synchrotron-based X-ray techniques such as high-resolution imaging microscopy and spectroscopy can be anticipated to deliver.

\section{References}

Al-Abed, S.R., G. Jegadeesan, K.G. Scheckel, and T. Tolaymat. 2008. Speciation, characterization, and mobility of $\mathrm{As}, \mathrm{Se}$, and $\mathrm{Hg}$ in flue gas desulphurization residues. Environ. Sci. Technol. 42:1693-1698. doi:10.1021/es702479n

Arai, Y., A. Lanzirotti, S. Sutton, J.A. Davis, and D.L. Sparks. 2003. Arsenic speciation and reactivity in poultry litter. Environ. Sci. Technol. 37:4083-4090 doi:10.1021/es0340580

Arai, Y., A. Lanzirotti, S. R. Sutton, Matthew Newville, J. Dyer, and D.L. Sparks. 2006. Spatial and temporal variability of arsenic solid-state speciation in historically lead arsenate contaminated soils. Environ. Sci. Technol. 40:673-679. doi:10.1021/es051266e

Attanayake, C., G.M. Hettiarachchi, Q. Ma, G.M. Pierzynski, and M. Ransom. 2017. Lead speciation and in vitro bioaccessibility of compost-amended urban garden soils. J. Environ. Qual. 46:1215-1224. doi:10.2134/ jeq2017.02.0065

Bacquart, T., G. Devès, A. Carmona, R. Tucoulou, S. Bohic, and R. Ortega. 2007. Subcellular speciation analysis of trace element oxidation states using synchrotron radiation micro-X-ray absorption near-edge structure, Anal. Chem. 79:73537359. doi: $10.1021 / \mathrm{ac} 0711135$
Baker, L., G.M. Pierzynski, G.M. Hettiarachchi, K.G. Scheckel, and M. Newville. 2012. Zinc speciation in proximity to phosphate application points in a lead/ zinc smelter-contaminated soil. J. Environ. Qual. 41:1865-1873. doi:10.2134/ jeq2012.0168

Balerina, A., and S. Mobilio. 2015. Introduction to synchrotron radiation. In: S. Mobilio, F. Boscherini, and C. Meneghini, editors, Synchrotron radiation. SpringerVerlag, Berlin, Heidelberg. doi:10.1007/978-3-642-55315-8_1

Behrens, S., A. Kappler, and M. Obst. 2012. Linking environmental processes to the in situ functioning of microorganisms by high-resolution secondary ion mass spectrometry (NanoSIMS) and scanning transmission X-ray microscopy (STXM). Environ. Microbiol. 14:2851-2869. doi:10.1111/j.1462-2920.2012.02724.x

Berthelin, J. 1991. Diversity of environmental biogeochemistry. Elsevier, New York.

Bhreasail, Á.N., P.D. Lee, C. O'Sullivan, C.H. Fenton, R. Hamilton, P. Rockett, and T. Connolley. 2012. In situ observation of cracks in frozen soil using synchrotron tomography. Permafrost Periglacial Processes 23:170-176. doi:10.1002/ppp.1737

Blamey, F.P.C., M.C. Hernandez-Soriano, M. Cheng, C. Tang, D.J. Paterson, E. Lombi et al. 2015. Synchrotron-based techniques shed light on mechanisms of plant sensitivity and tolerance to high manganese in the root environment. Plant Physiol. 169:2006-2020. doi:10.1104/pp.15.00726

Bodei, S., A, Manceau, N. Geoffroy, A. Baronnet, and M. Buatier. 2007. Formation of todorokite from vernadite in Ni-rich hemipelagic sediments. Geochim. Cosmochim. Acta 71:5698-5716. doi:10.1016/j.gca.2007.07.020

Burke, I.T., W.M. Mayes, C.L. Peacock, A.P. Brown, A.P. Jarvis, and K. Gruiz. 2012 Speciation of arsenic, chromium, and vanadium in red mud samples from the Ajka Spill Site, Hungary. Environ. Sci. Technol. 46:3085-3092. doi:10.1021/ es3003475

Burke, I.T., J. F. W. Mosselmans, S. Shaw, C. L. Peacock, L.G. Benning, V. S. Coker. 2015. Impact of the Diamond Light Source on research in Earth and environmental sciences: Current work and future perspectives. Philos. Trans. R. Soc., A 373:2036. doi:10.1098/rsta.2013.0151

Cances, B., F. Juillot, G. Morin, V. Laperche, L. Alvarez, O. Proux et al. 2005. XAS evidence of $\mathrm{As}(\mathrm{V})$ association with iron oxyhydroxides in a contaminated soil at a former arsenical insecticide processing plant. Environ. Sci. Technol. 39:93989405. doi:10.1021/es050920n

Castillo-Michel, H., J. Hernandez-Viezcas, K.M. Dokken, M.A. Marcus, J.R. PeraltaVidea, and J.L. Gardea-Torresdey. 2011. Localization and speciation of arsenic in soil and desert plant Parkinsonia florida using $\mu$-XRF and $\mu$-XANES. Environ. Sci. Technol. 45:7848-7854. doi:10.1021/es200632s

Chen, C. J.J. Dynes, J. Wang, C. Karunakaran, and D.L. Sparks. 2014. Soft X-ray spectromicroscopy study of mineral-organic matter associations in pasture soil clay fractions. Environ. Sci. Technol. 48:6678-6686. doi:10.1021/es405485a

Colzato, M., M. Kamogawa, H. Carvalho, L. Alleoni, and D. Hesterberg. 2017. Temporal changes in cadmium speciation in Brazilian soils evaluated using $\mathrm{Cd} \mathrm{L}_{\mathrm{UI}}{ }^{-}$ edge XANES and chemical fractionation. J. Environ. Qual. 46:1206-1214. doi: $10.2134 /$ jeq2016.08.0316

Datta, S., A.M. Rule, J.N. Mihalic, S.N. Chillrud, B.C. Bostick, J.P. Ramos-Bonilla et al. 2012. Use of $x$-ray absorption spectroscopy to speciate manganese in airborne particulate matter from five counties across the United States. Environ. Sci. Technol. 46:3101-3109. doi:10.1021/es203435n

de Jonge, M.D., C.G. Ryan, and C.J. Jacobsen. 2014. X-ray nanoprobes and diffractionlimited storage rings: Opportunities and challenges of fluorescence tomography of biological specimens. J. Synchrotron Radiat. 21:1031-1047. doi:10.1107/ S160057751401621X

Eriksson, M., and J.F. van der Veen, editors. 2014. Special issue on diffraction-limited storage rings and new science opportunities. J. Synch. Rad. 21 (part 5), p. $837-1216$.

Eriksson, M. J.F. van der Veen, and C. Quitmann. 2014. Diffraction-limited storage rings: A window to the science of tomorrow. J. Synch. Rad. 21:837-842. doi: $10.1107 /$ S1600577514019286

Etschmann, B.E., E. Donner, J. Brugger, D.L. Howard, M. de Jonge, D. Paterson et al. 2014. Speciation mapping of environmental samples using XANES imaging. Environ. Chem. 11:341-350. doi:10.1071/EN13189

Galkaduwa, M.B., G.M. Hettiarachchi, G.J. Kluitenberg, S.L. Hutchinson, L. Erickson, and L. Davis. 2017. Transport and transformation of selenium and other constituents of flue-gas desulfurization wastewater in water-saturated soil materials. J. Environ. Qual. 46:384-392. doi:10.2134/jeq2016.09.0335

Hesterberg, D.; I. McNulty, and J. Thieme. 2017. Speciation of soil phosphorus assess by XANES spectroscopy at different spatial scales. J. Environ. Qual. 46:11901197. doi:10.2134/jeq2016.11.0431

Hettiarachchi, G.M., K.G. Scheckel, J.A. Ryan, S.R. Sutton, and M. Newville. 2006. $\mu$-XANES and $\mu$-XRF investigations of metal binding mechanisms in biosolids. J. Environ. Qual. 35:342-351. doi:10.2134/jeq2004.0259

Hitchcock, A.P., M. Obst, J. Wang, Y.S. Lu, and T. Tyliszczak. 2012. Advances in the detection of As in environmental samples using low energy X-ray fluorescence in a scanning transmission X-ray microscope: Arsenic immobilization by an Fe(II)-oxidizing freshwater bacteria. Environ. Sci. Technol. 46:2821-2829. doi:10.1021/es202238k

Hitchcock, A.P., T. Tyliszczak, M. Obst, G.D.W. Swerhone, and J.R. Lawrence. 2010. Improving sensitivity in soft X-ray STXM using low energy X-ray fluorescence. Microsc. Microanal. 16:924-925. doi:10.1017/S1431927610054899 
Jacobsen, C., S. Wirick, G. Flynn, and C. Zimba. 2000. Soft X-ray spectroscopy from image sequences with sub-100 nm spatial resolution. J. Microsc. 197:173-184 doi:10.1046/j.1365-2818.2000.00640.x

Karna, R., G.M. Hettiarachchi, M. Newville, C.-J. Sun, and Q. Ma. 2016. Synchrotron-based X-ray spectroscopy studies for redox-based remediation of lead, zinc, and cadmium in mine waste materials. J. Environ. Qual. 45:1883-1893. doi:10.2134/jeq2015.12.0616

Karna, R., K. Scheckel, M. Noerpel, and A. Betts. 2017. Lead and arsenic bioaccessibility and speciation as a function of soil particle size. J. Environ. Qual. 46:1225-1235. doi:10.2134/jeq2016.10.0387

Kopittke, P., P. Wang, E. Lombi, and E. Donner. 2017. Synchrotron-based X-ray approaches for examining the toxic trace metal(loid)s in soil-plant systems. J. Environ. Qual. 46:1175-1189. doi:10.2134/jeq2016.09.0361

Kyriacou, B., K.L. Moore, D. Paterson, M.D. de Jonge, D.L. Howard, J. Stangoulis et al. 2014. Localization of iron in rice grain using synchrotron X-ray fluorescence microscopy and high resolution secondary ion mass spectrometry. J. Cereal Sci. 59:173-180. doi:10.1016/j.jcs.2013.12.006

Legros, S., P. Chaurand, J. Rose, A. Masion, V. Briois, J.H. Ferrasse et al. 2010. Investigation of copper speciation in pig slurry by a multitechnique approach. Environ. Sci. Technol. 44:6926-6932. doi:10.1021/es101651w

Lehmann, J., and D. Solomon. 2010. Organic carbon chemistry in soils observed by synchrotron-based spectroscopy. In: B. Singh and M. Gräfe, editors, Developments in soil science. Vol. 34. Elsevier, Burlington, MA. p. 289-312. doi:10.1016/S0166-2481(10)34010-4

Lehmann, J., D. Solomon, J. Kinyangi, L. Dathe, S. Wirick, and C. Jacobsen. 2008. Spatial complexity of soil organic matter forms at nanometer scales. Nat. Geosci. 1:238-242. doi:10.1038/ngeo 155

Lightsources. 2016. Lightsources of the world. Lighsources. http://www.lightsources. org/regions (accessed 16 Oct. 2017).

Llorens, I., E. Lahera, W. Delnet, O. Proux, A. Braillard, J.L. Hazemann et al. 2012. High energy resolution five-crystal spectrometer for high quality fluorescence and absorption measurements on an $\mathrm{x}$-ray absorption spectroscopy beamline. Rev. Sci. Instrum. 83:063104. doi:10.1063/1.4728414

Lombi, E., M.D. de Jonge, E. Donner, P.M. Kopittke, D.L. Howard, R. Kirkham et al. 2011a. Fast X-ray rluorescence microtomography of hydrated biological samples. PLoS ONE 6:e20626. doi:10.1371/journal.pone.0020626

Lombi, E., G.M. Hettiarachchi, and K.G. Scheckel. 201 b. Advanced in situ spectroscopic techniques and their applications in environmental biogeochemistry: Introduction to the special section. J. Environ. Qual. 40:659-666. doi:10.2134/ jeq2010.0542

Lombi, E., and J. Susini. 2009. Synchrotron-based techniques for plant and soil science: Opportunities, challenges and future perspectives. Plant Soil 320:1-35. doi: 10.1007/s11104-008-9876-x

Ma, Y., E. Lombi, A.L. Nolan, and M.J. McLaughlin. 2006. Short-term natural attenuation of copper in soils: Effects of time, temperature, and soil characteristics. Environ. Toxicol. Chem. 25:652-658. doi:10.1897/04-601R.1

Manceau, A., M. Enescu, A. Simionovici, M. Lanson, M. Gonzalez-Rey, M. Rovezzi et al. 2016. Chemical forms of mercury in human hair reveal sources of exposure. Environ. Sci. Technol. 50:10721-10729. doi:10.1021/acs.est.6b03468

Manceau, A., M.A. Marcus, N. Tamura, O. Proux, N. Geoffroy, and B. Lanson. 2004. Natural speciation of $\mathrm{Zn}$ at the micrometer scale in a clayey soil using X-ray fluorescence, absorption, and diffraction. Geochim. Cosmochim. Acta 68:24672483. doi:10.1016/j.gca.2003.11.021

Mariet, A., G. Sarret, C. Bégeot, A. Walter-Simonnet, and F. Gimbert. 2017. Lead highly available in soils centuries after metallurgical activities. J. Environ. Qual. 46:1236-1242. doi: $10.2134 /$ jeq2016.12.0469

Mitsunobu, S., F. Shiraishi, H. Makita, B.N. Orcutt, S. Kikuchi, B.B. Jorgensen, and Y. Takahashi. 2012. Bacteriogenic Fe(III) (oxyhydr)oxides characterized by synchrotron microprobe coupled with spatially resolved phylogenetic analysis. Environ. Sci. Technol. 46:3304-3311. doi:10.1021/es203860m

Moore, K.L., Y. Chen, A.M. van de Meene, L. Hughes, W. Liu, T. Geraki et al. 2014. Combined NanoSIMS and synchrotron X-ray fluorescence reveals distinct cellular and subcellular distribution patterns of trace elements in rice tissues. New Phytol. 201:104-115. doi:10.1111/nph.12497

Nachtegaal, M., M.A. Marcus, J.E. Sonke, J. Vangronsveld, K.J.T. Livi, D. van Der Lelie, and D.L. Sparks. 2005. Effects of in situ remediation on the speciation and bioavailability of zinc in a smelter contaminated soil. Geochim. Cosmochim. Acta 69:4649-4664. doi:10.1016/j.gca.2005.05.019

Net, W.D., I. Kieffer, E. Lahera, O. Proux, D. Testemale, Y. Joly et al. 2015. High energy resolution fluorescence detection X-ray absorption spectroscopy in environmental and earth sciences on CRG-FAME beamline at ESRF. Poster from the 16th International Conference on X-ray Absorption Fine Structure, Karlsruhe, Germany. 23-28 Aug. 2015. Eur. Synchrotron Radiation Facility, Grenoble, France. http:// www.esrf.eu/files/live/sites/www/files/UsersAndScience/Experiments/CRG/ BM16/Bibliography/Poster_FAME_XAFS_16.pdf(accessed 16 Oct. 2017).
Owen, R.L., J. Juanhuix, and M. Fuchs. 2016. Current advances in synchrotron radiation instrumentation for MX experiments. Arch. Biochem. Biophys. 602:2131. doi:10.1016/j.abb.2016.03.021

Papaefthimiou, V., T. Dintzer, V. Dupuis, A. Tamion, F. Tournus, D. Teschner et al. 2011. When a metastable oxide stabilizes at the nanoscale: Wurtzite $\mathrm{CoO}$ formation upon dealloying of PtCo nanoparticles. J. Phys. Chem. Lett. 2:900-904. doi:10.1021/jz2003155

Peth, S., C. Chenu, N. Leblond, A. Mordhorst, P. Garnier, N. Nunan et al. 2014. Localization of soil organic matter in soil aggregates using synchrotron-based X-ray microtomography. Soil Biol. Biochem. 78:189-194. doi:10.1016/j. soilbio.2014.07.024

Proux, O., E. Lahera, W. Del Net, I. Kieffer, M. Rovezzi, D. Testemale et al. 2017. High-energy resolution fluorescence detected X-ray absorption spectroscopy: A powerful new structural tool in environmental biogeochemistry sciences. J. Environ. Qual. 46:1146-1157. doi:10.2134/jeq2017.01.0023

Robertson, M. 1980. Biology in 19802, plus or minus a decade. Nature 285:358-359. doi: $10.1038 / 285358 \mathrm{a} 0$

Robinson, A.L. 2009. History of synchrotron radiation. 2009. In: X-ray data booklet. LBNL/PUV-490 Rev. 3. Lawrence Berkeley National Laboratory. http://xdb. lbl.gov/xdb-new.pdf (accessed 16 Oct. 2017).

Sarret, G., L. Avoscan, M. Carriere, R. Collins, N. Geoffroy, F. Carrot et al. 2005. Chemical forms of selenium in the metal-resistant bacteria Ralstonia metallidurans $\mathrm{CH} 34$ exposed to selenite and selenite. Appl. Environ. Microbiol. 71:2331-2337. doi:10.1128/AEM.71.5.2331-2337.2005

Sekine, R., E. Marzouk, M. Khaksar, K. Scheckel, J. Stegemeier, G. Lowry et al. 2017. Aging of dissolved copper and copper-based nanoparticles in five different soils: Short-term kinetics vs. long-term fate. J. Environ. Qual. 46:1198-1205. doi:10.2134/jeq2016.12.0485

Seyfferth, A.L., S.M. Webb, J.C. Andrews, and S. Fendorf. 2010. Arsenic localization, speciation, and co-occurrence with iron on rice (Oryza sativa L.) roots having variable Fe coatings. Environ. Sci. Technol. 44:8108-8113. doi:10.1021/es101139z

Smith, E., I.M. Kempson, A. Juhasz, J. Weber, W.M. Skinner, and M. Grafe. 2009a. Localization and speciation of arsenic and trace elements in rice tissues. Chemosphere, 4:529-535. doi:10.1016/j.chemosphere.2009.03.010

Smith, S.Y., M.E. Collinson, P.J. Rudall, D.A. Simpson, F. Marone, and M. Stampanoni . 2009. Virtual taphonomy using synchrotron tomographic microscopy reveals cryptic features and internal structure of modern and fossil plants. Proc. Natl. Acad. Sci. U. S. A. 106:12013-12018. doi:10.1073/pnas.0901468106

Solomon, D., J. Lehmann, J. Wang, J. Kinyangi, K. Heymann, Y.S. Lu et al. 2012. Micro- and nano-environments of $\mathrm{C}$ sequestration in soil: A multi-elemental STXM-NEXAFS assessment of black C and organomineral associations. Sci. Total Environ. 438:372-388. doi:10.1016/j.scitotenv.2012.08.071

Spielman-Sun, E., E. Lombi, E. Donner, D. Howard, J.M. Unrine, and G.V. Lowry. 2017. Impact of surface charge on cerium oxide nanoparticle uptake and translocation by wheat (Triticum aestivum). Environ. Sci. Technol. 51:7361-7368. doi:10.1021/acs.est.7b00813

Strawn, D.G, and L.L. Baker. 2009. Molecular characterization of copper in soils using X-ray absorption spectroscopy. Environ. Pollut. 157:2813-2821. doi:10.1016/j. envpol.2009.04.018

Stuckey, J., J. Yang, J. Wang, and D.L. Sparks. 2017. Advances in scanning transmission $\mathrm{X}$-ray microscopy for elucidating soil biogeochemical processes at the submicron scale. J. Environ. Qual. 46:1166-1174. doi:10.2134/jeq2016.10.0399

Sutton, S.R., A. Lanzirotti, M. Newville, M.L. Rivers, P. Eng, and L. Lefticariu. 2017. Spatially resolved elemental analysis, spectroscopy and diffraction at the GSECARS Sector at the Advance Photon Source. J. Environ. Qual. 46:1158-1165. doi:10.2134/jeq2016.10.0401

Swarbrick, J.C., U. Skyllberg, T. Karlsson, and P. Glatzel. 2009. High energy resolution X-ray absorption spectroscopy of environmentally relevant lead(II) compounds. Inorg. Chem. 48:10748-10756. doi:10.1021/ic9015299

Takahashi, Y., Y. Kanai, H. Kamioka, A. Ohta, H. Maruyama, Z. Song, and H. Shimizu. 2006. Speciation of sulfate in size-fractionated aerosol particles using sulfur K-edge X-ray absorption near-edge structure. Environ. Sci. Technol. 40:5052-5057. doi:10.1021/es060497y

Thieme, J., I. McNulty, S. Vogt, and D. Paterson. 2007. X-Ray spectromicroscopy: A tool for environmental sciences. Environ. Sci. Technol. 41:6885-6889. doi:10.1021/es0726254

Wallander, H., and J. Wallentin. 2017. Simulated sample heating from a nanofocused Xray beam. J. Synchrotron Radiat. 24:925-933. doi:10.1107/S1600577517008712

Wan, J., T. Tyliszczak, and T. K. Tokunaga. 2007. Organic carbon distribution, speciation, and elemental correlations within soil micro aggregates: Applications of STXM and NEXAFS spectroscopy. Geochimica et Cosmochimica Acta 71:5439-5449. doi:10.1016/j.gca.2007.07.030

Wang, W., A.N. Kravchenko, A.J.M. Smucker, W. Liang and M.L. Rivers. 2012. Intraaggregate pore characteristics: X-ray computed microtomography analysis. Soil Sci. Soc. Am. J. 76:1159-1171. doi:10.2136/sssaj2011.0281 